\title{
Membangun Excellence Service dan Hospitality Menuju Masa Depan Stifar Yayasan Pharmasi Semarang Yang Lebih Baik
}

\author{
Mahmud ${ }^{1}$, Diana Aqmala ${ }^{*}$ \\ ${ }^{1}$ Program Studi Manajemen, Fakultas Ekonomi dan Bisnis, Universitas Dian Nuswantoro, \\ Semarang, Indonesia \\ *Penulis korespondensi, email: diana.aqmala@gmail.com
}

\section{Submit : \\ 25 Juni 2020 \\ Diterima: \\ 25 Agustus 2020 \\ Terbit:}

31 Agustus 2020

\begin{abstract}
Abstrak. Sebuah organisasi dikatakan telah memberikan pelayanan prima bila pelayanan dan kualitasnya telah sesuai dengan harapan dan kebutuhan stakeholder. Melaksanakan pelayanan prima menjadi semakin penting dalam berbagai lingkungan yang kompetitif. Dinamika meningkatkan kepuasan pelanggan internal maupun pelanggan eksternal menjadi semakin lebih kompleks. Meskipun ada tantangan yang cukup besar dalam memberikan layanan yang berkualitas tinggi, pelayanan di perguruan tinggi telah mengalami pergeseran bertahap agar tercapai kepuasan pelanggan internal. Karyawan merupakan bagian dari aspek pelayanan yang berperan penting untuk meningkatkan kepuasan pelanggan. Salah satu faktor dapat yang meningkatkan keterampilan pelayanan karyawan adalah pelatihan. Tujuan dari diadakannya pelatihan ini adalah agar STIFAR Yayasan Pharmasi dapat memberikan pelayanan jasa pendidikan yang semakin baik dari waktu ke waktu agar mahasiswa maupun orang tua yang membiayai memperoleh kepuasan sesuai dengan ekspektasi yang diharapkan. Dengan terpenuhinya kepuasan konsumen yang ditunjang dari pemberian pelayanan secara prima akan berdampak signifikan bagi masa depan STIFAR Yayasan Pharmasi baik bertahan diindustri pendidikan tinggi, meningkatkan daya saing, ataupun memperluas pangsa pasar sehingga secara dapat menekan biaya operasional. Apabila tujuan tersebut mampu tercapai maka akan menjadi hal dan pengalaman yang dapat dijadikan bekal untuk para karyawan STIFAR Yayasan Pharmasi agar semakin baik dalam memberikan pelayanan, sehingga merasa betah pula untuk bekerja diinstitusi tersebut.
\end{abstract}

Kata Kunci: daya saing, pelatihan, service excellence, STIFAR Yayasan Pharmasi 


\section{PENDAHULUAN}

Melaksanakan pelayanan prima menjadi semakin penting dalam berbagai lingkungan yang kompetitif. Dinamika meningkatkan kepuasan pelanggan internal maupun pelanggan eksternal menjadi semakin lebih kompleks. Meskipun ada tantangan yang cukup besar dalam memberikan layanan yang berkualitas tinggi, pelayanan di perguruan tinggi telah mengalami pergeseran bertahap agar tercapai kepuasan pelanggan internal. Pergururuan tinggi sudah banyak yang mempromosikan keunggulan layanan dan mendorong kolaborasi namun relatif kurangnya sistem penghargaan kinerja yang terkait masih menjadi penghalang utama untuk menarik dan mempertahankan karyawan yang terampil dan berpengalaman.

Keterlibatan manajemen dan staf dalam melaksanakan pelayanan prima di perguruan tinggi dapat meningkatkan motivasi dan retensi staf. Memiliki budaya organisasi yang kuat dapat mendorong solidaritas di lingkungan kerja. Komunikasi yang lebih baik, kebersamaan yang lebih baik, memberi penghargaan dan menghargai pelanggan internal bisa memfasilitasi kinerja, inovasi, dan kepuasan pelanggan yang lebih besar, yang semuanya akan membantu perguruan tinggi mendapatkan dan mempertahankan keunggulan kompetitif yang khas dan berkelanjutan.

Astuti (2009) pada penelitian memaparkan 3 (tiga) dimensi utama yang dibutuhkan oleh mahasiswa dalam ruang lingkungan pendidikan, yaitu (1) respect for students (respek/pelayanan terhadap mahasiswa), (2) professor's knowledge (pengetahuan dosen), yang merupakan gambaran segala hal yang berkaitan dengan pengetahuan yang dipahami oleh dosen yang akan disampaikan kepada mahasiswa, dan (3) university physical environment (lingkungan fisik universitas atau perguruan tinggi), yang mencerminkan fasilitas-fasilitas yang tersedia baik di dalam ruang kuliah maupun di lingkungan kampus.

Sutopo dan Sanyoto (2006) menjelaskan bahwa pelayanan prima merupakan terjemahan dari istilah "Excellent Service" yang secara harfiah berarti pelayanan yang sangat baik dan atau pelayanan yang terbaik. Disebut sangat baik atau terbaik, karena sesuai dengan standar pelayanan yang berlaku atau dimiliki oleh instansi yang memberikan pelayanan. Apabila instansi pelayanan belum memiliki standar pelayanan, maka pelayanan disebut sangat baik atau terbaik atau akan menjadi prima, manakala dapat atau mampu memuaskan pihak yang dilayani (pelanggan). Jadi pelayanan prima dalam hal ini sesuai dengan harapan pelanggan.

Pelayanan prima merupakan suatu manajemen pelayanan, dimana lebih mengedepankan aspek mutu dan pengguna jasa pelayanan/ sasaran utama dari pelayanan prima adalah untuk meningkatkan kepuasan jasa pelayanan dan pelanggan (stakeholder). Stakeholder dalam instansi pendidikan adalah masyarakat yang peduli terhadap pelayanan pendidikan, baik public internal yang terdiri dari civitas akademika seperti dosen, mahasiswa, dan karyawan, maupun public eksternal yang terdiri dari orang tua, pemerintah, media, komunitas supplier dan pemangku kepentingan lainnya.

Dalam dunia pendidikan, jasa adalah 'produk' utama yang ditawarkan oleh sebuah instansi pendidikan kepada pelanggannya (stakeholder). Sebuah organisasi dikatakan telah memberikan pelayanan prima bila pelayanan dan kualitas yang dimiliki telah sesuai dengan harapan dan kebutuhan stakeholder. Bentuk pelayanan prima yang diberikan bermacam-macam, misalnya 
kepedulian karyawan kepada pelanggan, kesediaan karyawan mengambil resiko untuk pelanggan, kesediaan karyawan memberi solusi terhadap masalah-masalah pelanggan di masa depan.

Berdasarkan ulasan di atas karyawan merupakan bagian dari aspek pelayanan yang berperan penting untuk meningkatkan kepuasan pelanggan. Salah satu faktor dapat yang meningkatkan keterampilan pelayanan karyawan adalah pelatihan. Sesuai pendapat Noe (2003) karyawan lebih menyukai untuk belajar melalui pelatihan dimana dapat memberikan suatu kesempatan untuk melatih keterampilan. Salah satu bentuk pelatihan yang diharapkan dapat meningkatkan kualitas pelayanan di STIFAR Yayasan Pharmasi Semarang adalah pelatihan

'Membangun Excellence Service dan Hospitality Menuju Masa Depan Stifar Yayasan Pharmasi Semarang yang Lebih Baik'. Identifikasi Masalah Mitra

Persaingan antar penyedia jasa pelayanan pendidikan atau dalam hal ini adalah perguruan tinggi menunjukkan pola yang semakin baik. Pelayanan prima menjadi suatu bahan yang dijual oleh instansi untuk menarik pelanngan atau pengguna jasa. Apabila suatu instansi pendidikan tidak memberikan pelayanan yang sesuai dengan harapan pelanggan dikhawatirkan pelanggan akan memilih instansi lain yang sesuai dengan hapanannya. Perguruan tinggi berlomba-lomba menawarkan system pelayanan yang menimbulkan ekspektasi lebih dari pelanggan maupun maupun calon pelanggan. Namun masih ada beberapa aspek yang dilewatkan dalam implementasi pelayanan prima kepada pelanggan. Oleh karena itu perlu diadakan penyegaran terhadap psikologi dan pengetahuan karyawan terhadap pelayanan peima guna menigkatkan kualitas pelayanan yang dihasilkan oleh STIFAR Yayasan
Pharmasi Semarang melalui kegiatan pelatihan, seminar, maupun kegiatan lain yang sejenis.

\section{Rumusan Masalah}

Berdasarkan identifikasi masalah mitra diatas, maka perlu diadakan penyegaran terhadap psikologi dan pengetahuan karyawan terhadap pelayanan peima guna menigkatkan kualitas pelayanan yang dihasilkan oleh SRIFAR Yayasan Pharmasi Semarang melalui kegiatan pelatihan dan/atau seminar.

\section{Solusi Permasalahan}

Solusi permasalahan diatas adalah memberikan seminar Membangun Excellence Service dan Hospitality pada karyawan STIFAR Yayasan Pharmasi Semarang.

\section{Target}

Target program pengabdian masyarakat ini antara lain :
a. Karyawan STIFAR Yayasan

Pharmasi Semarang mampu memahami pentingnya pelayanan prima terhadap stakeholder
b. Karyawan STIFAR Yayasan Pharmasi Semarang mampu meningkatkan kualitas layanan terhadap stakeholder

c. Karyawan STIFAR Yayasan Pharmasi Semarang dapat menyadari bahwa kualitas pelayanan yang diberikan berdampak besar bagi perkembangan institusi.

\section{Luaran}

Luaran dalam program pengabdian masyarakat ini antara lain :
a. Karyawan
STIFAR
Yayasan Pharmasi Semarang memahami pentingnya pelayanan prima terhadap stakeholder

b. Karyawan STIFAR Yayasan Pharmasi Semarang meningkatkan kualitas layanan terhadap stakeholder

c. Karyawan STIFAR Yayasan Pharmasi Semarang menyadari bahwa kualitas pelayanan yang 
diberikan berdampak besar bagi perkembangan institusi.

\section{METODE}

Metode pelaksanaan kegiatan pengabdian masyarakat yaitu pelatihan Membangun Excellence Service dan Hospitality Menuju Masa Depan Stifar Yayasan Pharmasi Semarang yang Lebih Baik adalah menggunakan pendekatan pelatihan formal dan diskusi umum. Kegiatan tersebut sudah terlaksana dengan baik dengan metode pelatihan dan diskusi umum sebagai berikut:

a. Penyampaian materi pelayanan prima

Modul pelatihan Customer Service Excellence dibuat berdasarkan referensi yang berkaitan dengan layanan prima (Service Excellence). Sedangkan materi hospitality diperoleh dari referensi kasus yang terjadi pada rumah sakit. Materi pelatihan diawali dengan pengenal mengenai apa itu pelayanan kepada pelanggan dan bagaimana melakukannya. Tahap berikutnya para peserta diberikan pengetahuan mengenai apa yang dimaksud dengan Customer Service, siapa saja yang termasuk customer dan bagaimana membuat harapan customer menjadi kenyataan sehingga tercapai kepuasan customer. Salah satu indikator dari kepuasan pasien ialah jika mereka bahagia akan layanan yang diberikan.

b. Diskusi membangun pelayanan prima untuk meningkatkan kepuasan stakeholder

c. Tanya jawab santai dan tidak terlalu formal agar suasana tidak tegang

d. Simulasi dan penyegaran psikologi peserta pelatihan dengan games sederhana

\section{HASIL DAN PEMBAHASAN}

Berdasarkan hasil kegiatan pengabdian yang dilakukan di STIFAR Yayasan Pharmasi Semarang berupa pelatihan menunjukkan perubahan yang cukup signifikan pada penerapan pelayanan yang dilakukan oleh SDM dalam berkomunikasi hingga meyakinkan para pelanggannya untuk percaya pada kualtias yang diberikan STIFAR Yayasan Pharmasi Semarang. Pada saat pemberian materi komunikasi verbal dan komunikasi nonverbal dalam memberikan pelayanan kepada customer, mereka terlebih dahulu diberikan pengukuran terhadap pengetahuan awal atau dasar bagaimana berkomunikasi kepada para pelanggan. Setelah itu diberikan pelatihan beserta diskusi dan Tanya jawab menghasilkan bahwa tambahan informasi yang diberikan oleh narasumber membuat SDM STIFAR Yayasan Pharmasi Semarang lebih percaya diri dan yakin mampu memberikan pelayanan sesuai dengan yang diharapkan oleh institusi, sehingga dapat membantu institusi mencapai tujuan yang telah ditetapkan.

Peningkatan secara positif juga terlihat pada role play SDM STIFAR Yayasan Pharmasi Semarang yang cenderung lebih kaku kepada pelanggan karena belum diberi pelatihan menjadi lebih cakap dalam bersikap dan membangun brand image menghadapi berbagai macam karakteristik pelanggan beserta pertanyaan yang dibawanya. Contoh nyatanya ialah pada kepercayaan diri, tegur sapa, dan kemampuan menyelesaikan permasalahan yang dihadapi oleh pelanggan.

Walaupun peningkatan individu SDM telah terlihat hasilnya, pihak manajemen juga perlu menjaganya dengan penyelenggaraan iklim komunikasi dalam perusahaan secara efektif dan efisien agar membuat SDM STIFAR Yayasan Pharmasi Semarang merasa nyaman dan yakin untuk turut serta mengembangkan perusahaan dan meningkatkan daya saingnya di dalam industri. Selain itu, konsistensi penyelenggaraan pelatihan guna meningkatkan service excellent dan hospitality perlu diterapkan hingga ke setiap level divisi dalam perusahaan 
agar tujuan dapat tercapai sesuai dengan yang direncanakan.

\section{KESIMPULAN}

Pelatihan dan diskusi umum tentang pelayanan prima mampu menumbuhkan kesadaran pada karyawan STIFAR Yayasan Pharmasi Semarang akan pentingnya kualitas layanan yang dihasilkn oleh perguruan tinggi. Kegiatan ini juga meningkatkan semangat dan motovasi pada karyawan STIFAR Yayasan Pharmasi Semarang dalam meningkatkan kualitas pelayanan dan menggunakan prinsip pelayanan prima sebagai acuan dalam mempertahankan eksistemsi di tengah persaingan antar institusi pendidilan. Service excellence dan hospitality mampu meningkatkan kepuasan pengguna jasa dan pemangku kepentingan atau stakeholder terhadap perguruan tinggi.

\section{UCAPAN TERIMAKASIH}

Terimakasih kepada Dekan Fakultas Ekonomi dan Bisnis Universitas Dian Nuswantoro Semarang yang telah memberikan ijin bagi tim pengabdian untuk melaksanakan pengabdian kepada masyarakat di STIFAR Semarang serta kepada pimpinan STIFAR Semarang yaitu Dr. Apt. Endang Diyah Ikasari, M.Si yang telah memberikan kesempatan kepada tim pengabdian Fakultas Ekonomi dan Bisnis Universitas Dian Nuswantoro Semarang untuk berkontribusi dalam upaya peningkatan pelayanan prima di STIFAR Semarang.

\section{DAFTAR PUSTAKA}

Astuti, T.D. (2009). Analisis Perbedaan Harapan Kualitas Jasa Pendidikan (Studi Empiris Pada Program Studi Akuntans i Di Perguruan Tinggi Di Yogyakarta) Fenomena, Maret 2009, hal. 01-12 volume 7, nomor 1 ISSN 16934296. Program Studi Akuntansi Fakultas Ekonomi Dan Komunikasi Bisnis, Universitas Mercu Buana Yogyakarta

Khan, Hina and Harry Matlay, Implementing Service Excelence in Higher Education, Education + Training, Vol. 51 Iss: 8 pp. 769 - 780, 2009

Noe, R. M. 2003. Human Resource Management. Massachusets: Allyn Bacon.

Sutopo dan Suryanto, A. 2006.
Pelayanan Prima
Pendidikan Modul
Prajabatan Golongan III. Jakarta
: LAN

